\title{
Division of labor in complex societies: a new age of conceptual expansion and integrative analysis
}

\author{
Simon K. A. Robson ${ }^{1}$ - James F. A. Traniello ${ }^{2}$
}

Published online: 3 June 2016

(C) Springer-Verlag Berlin Heidelberg 2016

\begin{abstract}
In large cities... one man makes shoes for men, another for women, there are places even where one man earns a living just by mending shoes, another by cutting them out, another just by sewing the uppers together, while there is another who performs none of these operations but assembles the parts, Of necessity, he who pursues a very specialised task will do it best.
\end{abstract}

\section{Xenophon, Cyropaedia (2365 ybp)}

Ultrasociality refers to the most social of animal organizations, with full time division of labor, specialists who gather no food but are fed by others, sharing of information about sources of food and danger, and self-sacrificial effort in collective defense. This level has been achieved by ants, termites and humans in several scattered archaic city-states.

Campbell (1982)

Many writers have for a long time maintained that there is a division of labor among ants correlated with differences in size and structure. There are some differences

This manuscript is a contribution to the special issue Integrative Analysis of Division of Labor - Guest Editors: Simon K. Robson, James F.A. Traniello

James F. A. Traniello

jft@bu.edu

Simon K. A. Robson

simon.robson@jcu.edu.au

1 Terrestrial Ecosystems, James Cook University, Townsville, QLD 4811, Australia

2 Department of Biology, Boston University, Boston, MA 02215, USA of opinion as to the functions of different classes. Probably this is largely due to the fact that the observations were in many cases made upon different species.

Buckingham (1911)

The ancient reference by Xenophon and the neologism "ultrasociality" (Campbell 1982; Gowdy and Krall 2015) define division of labor as a significant commonality in the organization of insect and human societies, bridging disciplines across millennia and revealing overlap in historical and modern interests in the role of specialization in social structure. Within the time period encompassed by the Athenian record and modern bioeconomics lies the work of Adam Smith, Emile Durkheim, Henry Ford, Charles Darwin, William Morton Wheeler, Julian Huxley, and Edward O. Wilson, and an interdisciplinary interplay in conceptual development and application in social insect biology and beyond. This entomological and sociological dialogue and reciprocal exchange in modeling the organization of work (Rodgers 2008) has been significant to the study of social insect labor.

Today, unresolved issues and sometimes controversy concerning the degree of plasticity in social organization and how division of labor may be effectively examined at multiple levels form the core of research. The roots of some controversies appear to run deep. Buckingham (1911), for example, noted morphological evolution correlated with task specialization and described "differences of opinion" in respect to worker function associated with interspecific variation, naively but accurately anticipating some current disagreements that may derive from the biologies of model species. This special issue of Behavioral Ecology and Sociobiology is based on the symposium Integrative Analysis of Division of Labor 
convened at the 14th International Congress of the International Union for the Study of Social Insects, in Cairns, Australia, with additions. The symposium - and special issue-features contributions that celebrate the integrative, innovative, and sometimes provocative study of the organization of labor in insect societies.

We recognize The origin and evolution of polymorphism in ants (Wilson 1953) as a watershed event for constructing the conceptual foundation for the study of worker division of labor, leading to the genesis of an exceptionally broad descendant literature on the ecology of caste and mechanisms of task performance. Since the inception of this modern evolutionary analysis (Wilson 1953; Wilson 1968; Oster and Wilson 1978), genomics, bioinformatics, neuroscience, insect cognition, the study of interindividual variation and behavioral syndromes, self-organization theory, phylogenetic analysis, computational modeling, and computer vision have either emerged as new approaches or have expanded technologically to dramatically increase the size of the toolkit used to explore social organization. Theoretical and methodological advances complement descriptive and experimental field and laboratory studies of colony organization and worker behavior, thus facilitating the integration of multiple levels of analysis to advance our understanding of the ecology, evolution, and mechanisms of division of labor.

Recent analyses of division of labor have benefited from developments in sociogenomics (Rajakumar et al. 2012; Robinson et al. 2005), sociometry and sociogenesis (Wilson 1985; Tschinkel 2011), collective decision-making (Duarte et al. 2011), task allocation and social interaction (Gordon 2010), neuroanatomy (Menzel 2012), and neurochemistry (Schulz et al. 2002; Kamhi and Traniello 2013). Molecular phylogenies provide evolutionary insights (Moreau 2008; Economo et al. 2016; Price et al. 2016), and novel automated tracking methods and network analysis enable extensive and detailed data collection and descriptions of individual worker behavior (Mersch et al. 2013). Collateral developments in epigenetics (Alvarado et al. 2015; Glastad et al. 2015; Simola et al. 2016; Yan et al. 2015), social brain theory (Gronenberg and Riveros 2009; Lihoreau et al. 2012), social insect cognition (Avargues-Weber and Giurfa 2013), and brain miniaturization and mosaic structure (Eberhard and Wcislo 2012; Muscedere and Traniello 2012; O’Donnell et al. 2014) represent further advances. Model systems have expanded from the honey bee and the ant genus Pheidole in the past four decades, affording rich and novel opportunities to improve the breadth and resolution of research and test generalities derived from studies of focal species.

The collection of articles we present attempts to capture the integrative nature of and diverse perspectives on the organization of work in insect colonies. A major goal of research on social organization seeks to define the ecological factors and evolutionary processes that generate robust and adaptive systems of division of labor and discover ultimate and proximate causes of morphological and behavioral differentiation. The papers and commentaries included in this issue collectively present a microcosm of our current state of knowledge of the patterns and processes of division of labor, and identify challenges for future work. Contributors present reviews and original research papers that can be grouped into three categories, illustrating intrinsic and extrinsic influences on individual behavior and colony-level processes including developmental, interaction-based, life history-related, and ecological factors.

The first group of papers concerns the behavioral structure and basis of worker task schedules. Drawing on concepts of animal personality, Alexander Walton and Amy Toth examine behaviors in individual honey bee workers that remain constant over time, social context, and lifespan, and suggest that such variation is adaptive. Yuko Ulrich and coauthors describe how differences in responses to social cues from larvae influence behavior and reproductive physiology according to colony size in the raider ant Cerapachys biroi. Myrsini Natsopoulou and coauthors show how parasites affect the expression of division of labor in honey bees and demonstrate how infections by deformed wing virus or the microsporidian Nosema ceranae can adaptively accelerate the age-related task schedule of workers. Brian Johnson and William Jasper, using genomic tools, examine the regulation of the coordinated changes in behavior and physiology that drive age-related division of labor in the honey bee. They approach the ambitious goal of identifying "master caste regulators" that control social behavior using RNA-Seq to examine gene expression in tissues whose functions and products are predicted to vary with task specialization, and find only a small number of regulatory genes differentially expressed in sampled tissues.

The second group of articles considers division of labor within frameworks of caste evolution and evolutionary physiology. Christina Kwapich and Walter Tschinkel use field manipulations and laboratory studies of the Florida harvester ant Pogonomyrmex badius to illuminate the coupling of worker behavioral development, survivorship, and colony-level demand for foragers, and show that changes in the rate of worker development can enhance colony fitness. Jennifer Fewell and Jon Harrison use scaling to explore how changes in colony size influence the behavioral organization and efficiency of social insect colonies. Identifying whole-organism parallels, they find that larger colony sizes produce consistent changes in worker specialization, task performance, and the allocation of workers to maintenance rather than foraging or brood care behaviors. Ofer Feinerman and James Traniello integrate caste theory, social brain theory, brain metabolism, and brain evolution to examine the tradeoff between worker cognition and the energetic expense of producing and operating larger, energetically costly brains. Framing their study in the context of insect social brain theory (Lihoreau et al. 2012; Riveros et al. 
2012; Farris 2016), they focus on collective intelligence and division of labor as selective forces of brain evolution in respect to diet, the behavioral performance of individual workers, and social organization by modeling food availability, foraging behavior and related energetic gain, colony size, worker size and polymorphism, and brain size. Scott Powell comparatively analyzes the links between behavior, nesting ecology, and morphological caste evolution in turtle ants, genus Cephalotes. Building on studies that demonstrate a fitness payoff in the association of soldier head width and the size of the colony nest entrances for which their phragmotic heads serve as living doors, he suggests the emergence of new caste phenotypes reflects shifts in ecological specialization, while the distribution of traits within the range or morphological space reflects changes in resource utilization. Danielle Mersch embeds the study of division of labor firmly within the social environment as an emergent property based on the actions of individuals operating within a decentralized framework. She considers how large-scale patterns of interactions should be described and how they contribute to the maintenance of reliable and robust functioning at the colony level. Applying social network analysis, she establishes a framework for how we might, and might not, use these tools to describe and understand the structure of division of labor.

The special issue concludes with critical discussions of the relevance of continuing to use the term "division of labor" to understand how social insect colonies are organized. Deborah Gordon considers that the term describes a process and is misleading and of little value in revealing how social insect colonies function. She argues that support for the claim that division of labor reflects persistent internal states of workers and that morphologically differentiated workers are adapted to performing particular tasks to increase colony fitness is not compelling. The online publication of this paper elicited two responses. In his commentary on Gordon's paper, Robert Jeanne disagrees with her central premise, noting that the use of the term "division of labor" is widely acknowledged and accepted as a descriptor of a core component of colony phenotype that does not imply process, and recognizes interindividual variability in behavioral performance. Dhruba Naug similarly rejects the notion that division of labor implies persistent individual specialization and argues that both internal and external factors drive individual behavioral differences while highlighting the value of multiple approaches to understand the why and how of social insect organization.

In sum, the special issue presents diverse and complimentary approaches to understanding division of labor, all offering insightful answers to classical questions. The articles demonstrate the value of addressing basic questions using varied concepts and toolkits and the capacity to expand our understanding through integrative approaches. Our hope is that the attention given to the analysis of division of labor in this article collection will stimulate critical thinking and advance theory and empirical work across disciplines to move forward research on the ecology and mechanisms of division of labor. We also hope the special issue will enhance the conversation between insect science and bioeconomics and facilitate work on broader considerations such as the evolution of ultrasociality.

Since its first issue in 1976, Behavioral Ecology and Sociobiology has played a prominent role in publishing pathbreaking research on social insect division of labor. To facilitate further research and promote inquiry, the content of this special issue is extended by a virtual edition that includes the 25 highest-impact articles on the topic published in the journal. More than 160 papers on division of labor have appeared in $B E S$ since its inception, impressively generating in excess of 6000 citations and a combined $\mathrm{H}$ factor of 47 (Web of Science). A single download (http://www.springer.com/ journal/265) will make the 25 most highly cited papers readily accessible.

Acknowledgments We thank Theo Bakker for his review and providing an editorial for the special issue, and Sara Arganda, Andrew Hoadley, Ian Traniello, Glen Chilton, and Conrad Hoskin for helpful comments. William Murphy kindly shared the Xenophon reference. JFAT is supported by National Science Foundation grant IOS-1354291.

\section{Compliance with ethical standards}

Conflict of interest The authors declare that they have no conflict of interest.

\section{References}

Alvarado S, Rajakumar R, Abouheif E, Szyf M (2015) Epigenetic variation in the Egfr gene generates quantitative variation in a complex trait in ants. Nat Commun 6 (6513): doi:10.1038/ncomms 7513

Avargues-Weber A, Giurfa M (2013) Conceptual learning by miniature brains. Proc Royal Soc B 280 doi:10.1098/rspb.2013.1907

Buckingham EN (1911) Division of labor among ants. Proc Am Acad Arts Sci 46:425-507

Duarte A, Weissing FJ, Pen I, Keller L (2011) An evolutionary perspective on self-organized division of labor in social insects. Annu Rev Ecol Evol Syst 42:91-110. doi:10.1146/annurev-ecolsys-102710145017

Eberhard WG, Wcislo WT (2012) Plenty of room at the bottom? Tiny animals solve problems of housing and maintaining oversized brains, shedding new light on nervous-system evolution. Am Sci 100:226-233

Economo EP, Klimov P, Sarnat EM, Guénard B, Weiser MD, Lecroq B, Knowles LL (2016) Global phylogenetic structure of the hyperdiverse ant genus Pheidole reveals the repeated evolution of macroecological patterns. Proc R Soc B. doi:10.1098/rspb.2014. 1416

Farris SM (2016) Insect societies and the social brain. Curr Opin Ins Sci 15:1-8. doi:10.1016/j.cois.2016.01.010

Glastad KM, Chau LM, Goodisman MAD (2015) Epigenetics in social insects. Adv Ins Physiol 48:227-269. doi:10.1016/bs.aiip.2014.12. 007

Gordon DM (2010) Ant encounters: interaction networks and colony behavior. Princeton University Press, Princeton, New Jersey 
Gowdy J, Krall L (2015) The economic origins of ultrasociality. Behav Brain Sci. doi:10.1017/S0140525X1500059X

Gronenberg W, Riveros AJ (2009) Social brains and behavior — past and present. In: Gadau J, Fewell J (eds) Organization of insect societies: from genome to sociocomplexity. Harvard University Press, Cambridge, pp 377-401

Kamhi JF, Traniello JFA (2013) Biogenic amines and collective organization in a superorganism: neuromodulation of social behavior in ants. Brain Behav Evol 82:220-236. doi:10.1159/ 000356091

Lihoreau M, Latty T, Chittka L (2012) An exploration of the social brain hypothesis in insects. Front Physiol 3:442. doi:10.3389/fphys.2012. 00442

Menzel R (2012) The honeybee as a model for understanding the basis of cognition. Nature Rev Neurosci 13:758-768. doi:10. 1038/nrn3357

Mersch DP, Crespi A, Keller L (2013) Tracking individuals shows spatial fidelity is a key regulator of ant social organization. Science 340 : 1090-1093. doi:10.1126/science. 1234316

Moreau CS (2008) Unraveling the evolutionary history of the hyperdiverse ant genus Pheidole (Hymenoptera: Formicidae). Mol Phylogenet Evol 48:224-239

Muscedere ML, Traniello JFA (2012) Division of labor in the hyperdiverse ant genus Pheidole is associated with distinct subcaste- and age-related patterns of worker brain organization. PLoS ONE 7 doi:10.1371/journal.pone.0031618

O'Donnell S, Clifford MR, Deleon S, Papa C, Zahedi N, Bulova SJ (2014) A test of neuroecological predictions using paperwasp caste differences in brain structure (Hymenoptera: Vespidae). Behav Ecol Sociobiol 68:529-536

Oster GF, Wilson EO (1978) Caste and ecology in the social insects. Princeton University Press, Princeton
Price S, Etienne RS, Powell S (2016) Tightly congruent bursts of lineage and phenotypic diversification identified in a continental ant radiation. Evolution 70:903-912. doi:10.1111/evo.12894

Rajakumar R, San Mauro D, Dijkstra MB, Huang MH, Wheeler DE, Hiou-Tim F, Khila A, Cournoyea M, Abouheif E (2012) Ancestral developmental potential facilitates parallel evolution in ants. Science 335:79-82

Riveros AJ, Seid MA, Wcislo WT (2012) Evolution of brain size in classbased societies of fungus-growing ants (Attini). Anim Behav 83: 1043-1049. doi:10.1016/j.anbehav.2012.01.032

Robinson GE, Grozinger CM, Whitfield CW (2005) Sociogenomics: social life in molecular terms. Nat Rev Genet 6:257-271. doi:10. $1038 / \operatorname{nrg} 1575$

Rodgers DM (2008) Debugging the link between social theory and social insects. Louisiana State University Press, Baton Rouge, Louisiana

Schulz DJ, Barron AB, Robinson GE (2002) A role for octopamine in honey bee division of labor. Brain Behav Evol 60:350-359

Simola DF, Graham RJ, Brady CM, Enzmann BL, Desplan C, Ray A, Zwiebel LJ, Bonasio R, Reinberg D, Liebig J, Berger SL (2016) Epigenetic (re)programming of caste-specific behavior in the ant Camponotus floridanus. Science 351:aac6633-1-aac6633-9

Tschinkel WR (2011) Back to basics: sociometry and sociogenesis of ant societies (Hymenoptera: Formicidae). Myrmecol News 14:49-54

Wilson EO (1953) The origin and evolution of polymorphism in ants. Q Rev Biol 28:136-156

Wilson EO (1968) The ergonomics of caste in the social insects. Am Nat $102: 41-66$

Wilson EO (1985) The sociogenesis of insect colonies. Science 228: $1489-1495$

Yan H, Bonasio R, Simola DF, Liebig J, Berger SL, Reinberg D (2015) DNA Methylation in social insects: how epigenetics can control behavior and longevity. In: Berenbaum MR (ed) Annu Rev Entomol, Vol 60, pp 435-452 